\title{
Assessing Barriers to Contraceptive Use amongst Adolescents in the Safroko Chiefdom, Bombali District, North East of Sierra Leone
}

\author{
${ }^{1}$ Evelyn Abie Bangura, ${ }^{2}$ Allieu Badara Kabia, ${ }^{3}$ Mohamed Gbeshay Sheku, ${ }^{4}$ Fawulay Yibba Marah, ${ }^{5}$ Magenda Kamara, \\ ${ }^{6}$ Issa Bangura, ${ }^{7}$ Morlai Francis Kargbo \\ ${ }^{1}$ Department of Nursing, Ernest Bai Koroma University of Science and Technology (EBKUST), Sierra Leone \\ ${ }^{2}$ Faculty of Social and Management Sciences, Ernest Bai Koroma University of Science and Technology (EBKUST), Sierra \\ Leone \\ ${ }^{3}$ Regional Government Hospital Makeni City, Ministry of Health and Sanitation (MHS), Sierra Leone \\ ${ }^{4}$ Department of Political Science, Development Studies and Law, Ernest Bai Koroma University of Science and Technology \\ (EBKUST), Sierra Leone \\ ${ }^{5}$ Department of Sociology and Social Work, Ernest Bai Koroma University of Science and Technology (EBKUST), Sierra Leone \\ ${ }^{6,7}$ Department of Economics, Accounting and Finance and Sociology/ Social Work, Ernest Bai Koroma University of Science and \\ Technology (EBKUST), Sierra Leone
}

Abstract - At least 200 million women want to use safe and effective family planning methods, but are unable to do so because they lack access to information and services or the support of their husbands and communities according to UNFPA.

In a country like Sierra Leone where access to family planning is limited and coupled with the religious and cultural beliefs and practices, many of the women and especially those in the rural areas face numerous barriers to accessing and utilizing family planning services. Understanding some of these barriers can contribute to the development of health promotion strategies and/or influencing policy development in the promotion of family planning uptake not only in the study community but the country as a whole. The main aim is to investigate factors that limit access and utilization of family planning services by adolescents in the study area. A descriptive crosssectional study was carried out. Respondents were selected using multi-stage sampling technique. Questionnaires and observational checklists were used for data collection. Data were analyzed using Excel.

The results revealed that, a total of 261 respondents were interviewed about the use of contraceptives, $64 \%$ are using modern methods, $18 \%$ are using natural method. $53 \%$ of the respondents are using family planning to prevent unwanted pregnancy, $\mathbf{4 2 . 6 \%}$ said it was not easy to get family planning commodities. $39 \%$ of the respondents got their information from health workers. The study further revealed that Individual and community characteristics were significant predictors of use of modern contraceptives in Safroko limba chiefdom and thus these factors should be taken into account in programming for family planning in the country.

Keywords: Contraceptive, Barriers, Adolescents, Safroko Chiefdom, Bombali District, Sierra Leone.

\section{INTRODUCTION}

Access to contraceptives is a basic reproductive right, and essential to avoid unintended and untimely pregnancies which have become a rising public health hazard issue in Sierra Leone. Early pregnancy, among adolescents aged 12-19 years, $28 \%$ had already begun childbearing and $24 \%$ of those married have had their first birth during the first year of marriage. Also, a larger proportion of teenage pregnancies occur in rural areas $-34 \%$ compared with $19 \%$ in urban areas. (NSRDP, 2018)

Due to a combination of biological, social and psychological factors, adolescents are more vulnerable to a range of health problems such as Sexually Transmitted Infections (STIs), HIV, early and repeated pregnancies. Nonetheless adolescents are very energetic and receptive to information that is applicable to them. However, sexual and reproductive health education and services are limited amongst communities in Sub-Sahara Africa especially the West African Block.

Research scholars have also proven that about 16 million women of the ages of 15 to 19 years old give birth each year, which is equivalent to $11 \%$ of all births worldwide. Sierra Leone culture forbids adolescent pregnancy because it is seen as an anti-traditional -cultural act and normally referred to as disaster to all concerned; that is, the girl, her family, the health 
services, the education authorities and society in general. As a matter of fact, the society norms do not permit unmarried girls to get pregnant irrespective of their ages (WHO, 2008). Despite the increase in contraceptive awareness in our society today, unwanted pregnancy still prevails amongst adolescents. The availability of contraceptives does not guarantee the fact that adolescents are free from teenage pregnancy as the low knowledge and use of contraceptive have made many adolescents victims of unwanted pregnancy. Contraception is practiced for pregnancy planning, limiting the number of children, controlling the world's population and other health related benefits. The use of contraception is increasing in developing countries but some forms are economically out of reach of those in developing countries.

All over the world, civilization has enable people to control reproduction and in some parts of the world, information about contraceptive is readily available. It is therefore questionable whether our adolescents are really aware of these contraceptive methods and know where to look for them.

The Government of Sierra Leone and its development partners as well as international NGOs have been implementing activities to improve the use of contraceptives for several decades. Although some progress has been made especially in the area of knowledge, a large number of Sierra Leonean female adolescents rarely use modern contraceptives (UNICEF, 2010). Education on contraceptives need to be intensified among adolescents to enable them protect themselves from unplanned pregnancies, unsafe abortions and STIs.

World Health Organization (WHO) defines adolescent as a person between the ages of 15-19 years, other studies define an adolescent as a person aged between 15-24 years. Under the second definition, these adolescents are sub-divided into late adolescent (15-19 years) and young adult (20-24 years) (WHO, 2010). However, irrespective of the age definition this target group is often faced with transitional changes that are biological, psychological and economical. These changes make coping mechanisms rather hard for especially the female adolescents resulting into unintended pregnancies and criminal abortions; respectively with the associated consequences. Adolescence stage is often the time when individuals begin to explore their sexuality and sexual relationships. This expression of sexual desire among the adolescents is influenced by several factors including family values, culture and religion among others [WHO, 2010]. Several studies have concluded that allowing adolescents to have full access to contraceptives remains the best approach of ensuring a healthy reproductive living. Such approach is not to be taken as a form of promoting promiscuity but rather a means of minimizing abortion, morbidity and mortality among the adolescents. Higher education among adolescents facilitates acquisition of knowledge on particular methods as well as how to acquire these contraceptive products. Studies have shown that sex education among adolescents plays an important role in increasing knowledge and empowering young people, especially against unwanted pregnancy [WHO, 2012]. These studies have also revealed lack of capacity among adolescents to negotiate for safer sex especially from the older persons.

Whereas most of the studies on contraceptives have been focusing on married women [UNFPA 2009], this study focuses on all the female adolescents aged 15-19 years so as to understand some of the predictors to their use of contraception.

In Sierra Leone contextual environment, Adolescent pregnancy and early child married have become a socioeconomic and health risk that has tendencies to threaten the sustainable development of the human capital to be specific and the Country as a whole. This vulnerability is as a result of the low use and lack of awareness of using contraceptives to mitigate the risk involved. Addendum to the aforesaid, it sometimes incubate to high rate of dropout from schools and colleges/universities, idle youths in clubs, entertainment centers, 'Ataya base' and 'ghetos' and this will incubate to social unrest which has been one of the recipes of the 11 years civil war that started in 1991 and ended in 2002 in Sierra Leone. It's as a result of this backdrop that insinuated the researcher to embark on this study with clear details on the problem as stated in 1.2.

The current study focuses on adolescents that are sexually active whether married or not. We also seek to establish the influence history of a previous birth and age first birth would have on utilization of contraceptives.

\section{AIM AND OBJECTIVES OF THE STUDY}

\subsection{Aim of the Research Study}

The aim of this study is to investigate factors that limit access and utilization of contraceptives by adolescents in the Safroko Chiefdom, Bombali District North-East Sierra Leone.

\subsection{Specific Objectives}

i. To assess the level of awareness and knowledge on contraceptives use amongst adolescence in the Safroko Chiefdom, Bombali District North-East Sierra Leone.

ii. To determine the availability of contraceptives use amongst adolescence in the Safroko Chiefdom, Bombali District North-East Sierra Leone. 
ISSN (online): 2581-3048

iii. To determine the barriers to accessing contraceptives use amongst adolescence in the Safroko Chiefdom, Bombali District North-East Sierra Leone.

iv. To make recommendations as per findings that will improve on contraceptives use amongst adolescence in the Safroko Chiefdom, Bombali District in particular and Sierra Leone as a whole.

\section{METHODOLOGY}

This study was a descriptive/cross sectional study to identify barriers to contraceptive use among adolescent in Safroko Chiefdom Bombali District North-East Sierra Leone. The source populations for study were all adolescent females living in the Chiefdom during the time of the study.

The study population was selected amongst sexually active adolescent females whose ages were 12-19. A structured questionnaire was administered to generate data identifying knowledge and barriers to contraceptive use by these adolescent females.

\subsection{Study area}

Safroko Chiefdom is one of the fourteen chiefdoms in Bombali district in the Northern Province of Sierra Leone. It borders with Bumbuna in Tonkolili District in the North, Makeni in the North-East, and Kamabia in the North-west. It occupies a total area of 1,370.8 kilo metres squares miles with a total population of 38,939 according to the population statistics (2015 population census).

It comprises of nine (9) Sections and the Chiefdom headquarter is Binkolo town. The nine sections are; Binkolo, Maboleh, Mathankeh, Mapam, makanthen, Katekoh, Malimboing, masolokoin and Makanka. Each section is headed by a Section Chief. The main ethnic groups are the Limbas and the Themnes. The Chiefdom is predominantly Christian.

The main economic activities are farming and palm wine tapping. The Predominant crops grow in the chiefdom are rice, groundnut, and citrus. Few people embark on goat and sheep rearing.

There are five (5) primary schools, two (2) Junior Secondary Schools and two senior secondary schools in the chiefdom. They are owned by the catholic mission and Wesleyan church of sierra Leone.

There are 10 Primary Healthcare Units (PHUs) in Safroko Chiefdom; 2 Community Health Centers (CHC), 1 Community Health Post (CHP) and 7 Maternal and Child Health Post (MCHP). The Community Health Centre (CHC) is located at the chiefdom headquarters town (Binkolo). The referral Hospital is located in Makeni town which is about six miles from Binkolo. There are lots of drug peddlers and traditional healers within the chiefdom. The diseases that are causing high morbidity and mortality in Safroko are: Malaria, Respiratory Tract Infections, Malnutrition, Diarrhoea, Dysentery and Sexually transmitted infection including H.I.V /AIDS.

\subsection{Data collection method and tools}

A structured and open ended questionnaire was used to collect data in the study area. It was designed purposely to address the objectives of the study.

\subsection{Sample and Sampling technique}

\subsubsection{Sample size determination}

The minimum sample size was determined using Fisher's formula $(n=Z 2 p q / d 2)$ for estimating sample size where the population is greater than 10,000

The population size of Safroko Chiefdom as of 2015 was 38,939 (Population and housing census report of Sierra Leone 2015). Adolescent population $(8.4 \%$ of 38,939$)=3271$

The following Fisher's formula was used to estimate the sample size.

$$
\mathrm{N}=\frac{\mathrm{z}^{2} \mathrm{Pq}}{\mathrm{d}^{2}}
$$

Where $\mathrm{N}=$ desired minimum sample size.

$\mathrm{Z}=1.96$ (The standard normal deviation usually corresponding to $95 \%$ confidence level).

$\mathrm{P}=$ the known characteristic of the study population. In this study, national estimate of contraceptive use among adolescent population is, $21.7 \%$ (DHS, 2013) which becomes our p.

$\mathrm{P}=0.217 ; \mathrm{Q}=1-\mathrm{P}=(1-0.217)=0.783 ; \mathrm{d}=$ degree of accuracy desired, set at 0.05

Thus $\mathrm{N}=(1.96)^{2}(0.217)(0.783) /(0.05)^{2}=261$; The population size for this study is therefore 261 .

\subsubsection{Sampling technique}

All nine (9) sections in the chiefdom were purposively sampled. A random sampling technique was done to determine who to interview and a sample size of 261 obtained. The number of adolescents Sampled from each section was proportional to the size of the population in the catchment area. 
ISSN (online): 2581-3048

\subsection{Quality control}

The following steps were used to ensure quality in the course of the study. The interview schedules were conducted in local languages (Limba and Themne) and back to English to confirm the meaning. This was to ensure common understanding and meaning to avoid misunderstanding during the data collection. The questionnaire was pre tested in area similar to the study area and mistakes were rectified. All completed questionnaires were check at the end of each interview for their completeness and consistency. The researcher was responsible for the distribution and collection of the questionnaires to ensure quality of data.

\subsection{Data collection procedure}

The questionnaires were first pre-tested and necessary corrections were made. Each section within the chiefdom was selected and proportional representative was ensured.

\subsection{Data analysis}

Editing and cleaning was done on the completed questionnaires; the researcher used Microsoft excels and word computer software to enter and analyzed the complied data. Results were then presented in tables, figures and graphs/ charts. Descriptive statistics were used to achieve the study objectives.

\subsection{Ethical considerations}

Prior to conducting interviews, the research protocolincluding the study design, questionnaire, informed consent, procedure and means of preserving respondents confidentiality was reviewed and approved by my supervisor Mrs. Fatmata Gegbe, school of Community Health Sciences, Bo campus, Njala University.

Permission to conduct the study was sought from Dr. Foday Sesay who is the District medical officer of Bombali District located in Makeni city. The questionnaires were administered in the nine different sections after obtaining permission from the in - Charge of each participating Health Center staff.

The objectives of the study were explained to study participants and Verbal consent from subjects was obtained. Privacy and confidentiality of collected information was ensured at all levels.

\section{RESULT/FINDINGS}

The results and interpretation of both quantitative and qualitative data are presented both in texts, percentages, graphs, figures and tables.
The findings are presented in the following sections: socio- demographic details of respondents, Level of awareness and knowledge of Contraceptive use among respondents, Availability of contraceptives and barriers among respondents who are female adolescence.

\subsection{Section A: Socio- Demographic Data of respondents}

Table 1: Socio- Demographic Data of respondents

\begin{tabular}{|c|c|c|c|}
\hline Variables & Options & Frequency $(\mathbf{N}=261$ & $\%$ \\
\hline \multirow[t]{3}{*}{ Age } & 12 to 14 & 68 & 26.05 \\
\hline & $15-19$ & 193 & 73.95 \\
\hline & Total & 261 & 100 \\
\hline \multirow{4}{*}{$\begin{array}{l}\text { Marital } \\
\text { status }\end{array}$} & Married & 20 & 7.66 \\
\hline & Single & 235 & 90.04 \\
\hline & $\begin{array}{l}\text { Divorce/separate/Wid } \\
\text { ow }\end{array}$ & 6 & 2.30 \\
\hline & Total & 261 & 100 \\
\hline \multirow{5}{*}{$\begin{array}{l}\text { Level of } \\
\text { education }\end{array}$} & Non-formal education & 20 & 7.66 \\
\hline & Primary & 108 & 41.38 \\
\hline & Secondary & 133 & 50.96 \\
\hline & Tertiary & 0 & 0 \\
\hline & Total & 261 & 100 \\
\hline \multirow{5}{*}{$\begin{array}{l}\text { Source of } \\
\text { income }\end{array}$} & Salary & 0 & 0 \\
\hline & Siblings & 105 & 40.23 \\
\hline & Non & 0 & 0 \\
\hline & Parent & 156 & 59.77 \\
\hline & Total & 261 & 100 \\
\hline \multirow[t]{4}{*}{ Religion } & Christianity & 156 & 59.77 \\
\hline & Islam & 105 & 40.23 \\
\hline & Traditional & 0 & 0 \\
\hline & Total & 261 & 100 \\
\hline \multirow[t]{5}{*}{ Ethnicity } & Limba & 176 & 67.43 \\
\hline & Themne & 59 & 22.61 \\
\hline & Loko & 8 & 3.06 \\
\hline & Other specify & 18 & 6.9 \\
\hline & Total & 261 & 100 \\
\hline
\end{tabular}

As indicated in table 1 , of the 261 respondents, all representing a $100 \%$ response rate were involved in the study. More than half of the respondents recorded 193 (73.95\%) 
ISSN (online): 2581-3048

were aged 15-19 years, whereas the remaining 68 respondents $(26.05 \%)$ accounted for those aged $12-14$ years.

Also, Most of the respondents about 235(90.04\%) are single while as 20 of the respondents $(7.66 \%)$ were married and 6 respondents $(2.3 \%)$ have either separated, divorced or have lost their spouse.

Furthermore, Out of the total number of 261 respondents, $20(7.66 \%)$ had no formal education. The respondents that have Secondary education are the highest recorded 133 (50.96\%) and seconded by 108 respondents (41.38\%) for primary education and none of the respondents had tertiary education. Addendum to aforesaid, respondents who had their income from their parents made up the majority recording
$156(59.77 \%)$ and $105(40.23 \%)$ had their income from their siblings. None of the respondents received income from salary.

The tables also revealed that more than half of the respondents $156(59.77 \%)$ are Christians and 105 respondents (40.23\%) are Islam.

Table 1 also revealed that more than half of the respondents were from the Limba ethnic group recorded 176 $(67.43 \%)$ followed the Themne with 59 respondents $(22.61 \%)$. The respondents from the Loko ethnic group recorded $8(3.06 \%)$ whilst any other tribe excluding the aforementioned recorded 18 respondents $(6.9 \%)$.

\subsection{Section B: Result estimates based on the Research Objectives}

\subsubsection{Level of awareness and Knowledge of Contraceptives use among Adolescents}

Table 2: Awareness of the use of Contraceptives among Adolescents

\begin{tabular}{|c|c|c|c|}
\hline Variables & Option & Frequency $(\mathrm{N}=\mathbf{2 6 1})$ & $\%$ \\
\hline \multirow{2}{*}{ Heard of contraceptive use among Adolescents } & Yes & 164 & 62.84 \\
\hline & No & 97 & 37.16 \\
\hline & Total & 261 & 100 \\
\hline \multirow{5}{*}{ Sources of information $(n=164)$} & Health worker & 64 & 39.02 \\
\hline & Friend/ Relative & 52 & 31.71 \\
\hline & Mass media & 36 & 21.95 \\
\hline & School & 5 & 3.05 \\
\hline & Neighbuor & 7 & 4.27 \\
\hline & Total & 164 & 100 \\
\hline \multirow{9}{*}{ Method(s) heard } & Male condom & 5 & 3.05 \\
\hline & Natural & 30 & 18.29 \\
\hline & Pills & 67 & 40.85 \\
\hline & Injectable & 30 & 18.29 \\
\hline & IUCD & 26 & 15.85 \\
\hline & Female condom & 0 & 0.00 \\
\hline & Traditional & 6 & 3.66 \\
\hline & Other (specify) & 0 & 0.00 \\
\hline & Total & 164 & 100 \\
\hline
\end{tabular}


ISSN (online): 2581-3048

Volume 5, Issue 6, pp 45-57, June-2021 https://doi.org/10.47001/IRJIET/2021.506010

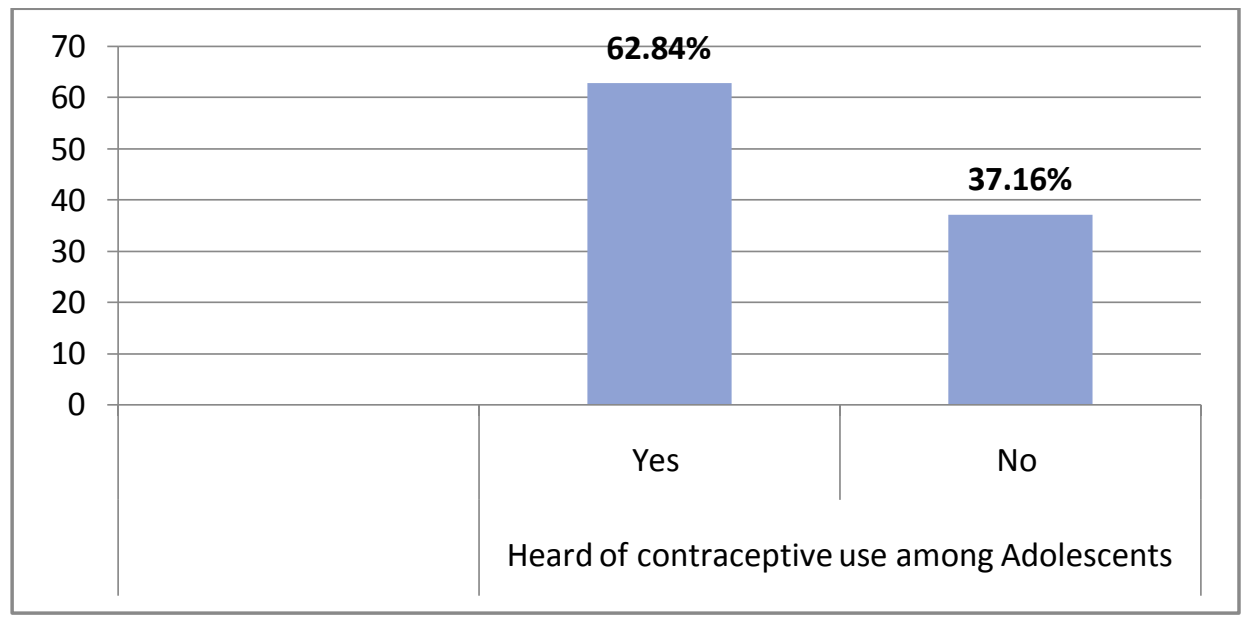

Figure 1: Percentages of respondent who heard awareness and knowledge of contraceptives use

Figure 1 revealed that 164 respondents (62.84\%) out of 261 respondents have heard and aware of the use of contraceptives while 97 respondents $(37.16 \%)$ have never heard about contraceptive use.

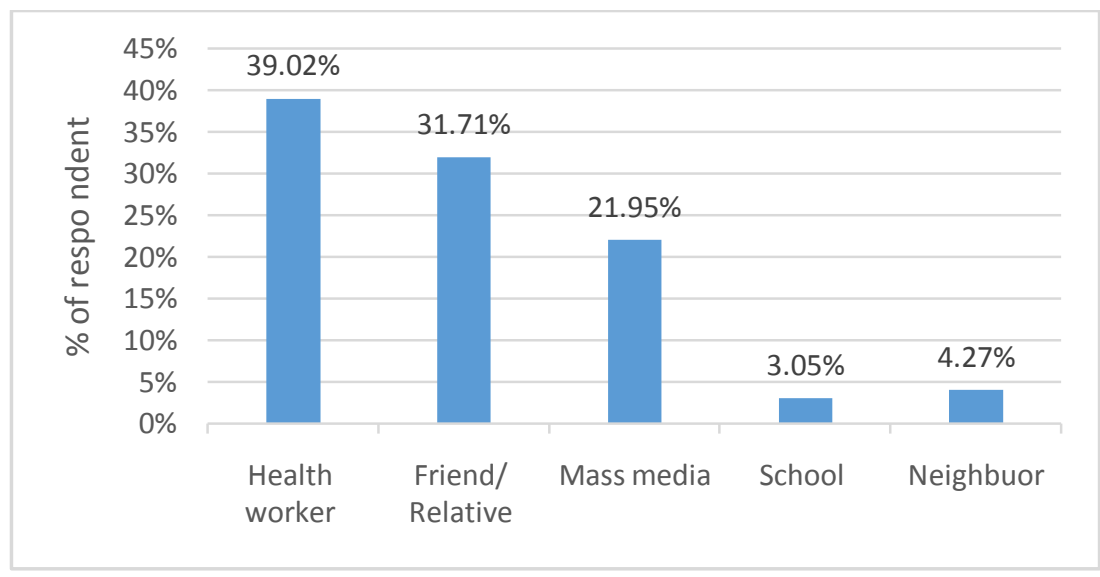

Figure 2: Percentages of sources of information among respondents $(n=164)$

From figure 2 above, out of the 261 respondents, only 164 respondents are aware of the use of contraceptives amongst adolescence. Out of the 164 respondents indicated above; 64 respondents (39.02\%) got their information from health workers, followed by 52 respondents $(31.71 \%)$ from friends or relatives whilst 36 respondents (21.95\%) from mass media and 12 respondents $(7.32 \%)$ got their information from schools and neighbors.

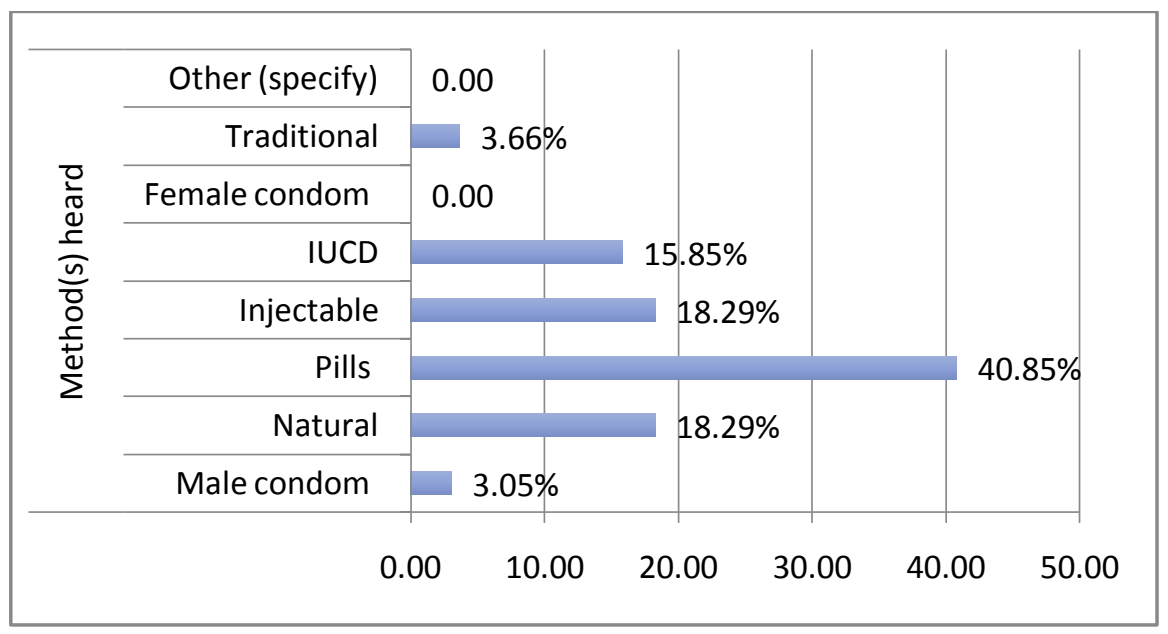

Figure 3: Shows contraceptives method(s) heard among respondents $(N=164)$ 
ISSN (online): 2581-3048

Figure 3 revealed that majority of the respondents recording $67(40.85 \%)$ have heard about the pills as a method of contraception followed by injectable and natural methods each recording 30 respondents (18.29\%) and IUCD methods with 26 respondents $(15.85 \%)$ each and traditional methods with 6 respondents $(3.66 \%)$. 5 respondents $(3.05 \%)$ recorded for male condom and none for female condom.

\subsubsection{Section C: Contraceptives use and barriers among respondents}

Table 3: Contraceptives use and barriers among respondents

\begin{tabular}{|c|c|c|c|}
\hline \multicolumn{4}{|c|}{ Contraceptives use and barriers among Adolescents } \\
\hline \multirow{2}{*}{ Used of_contraception } & Yes & 94 & 57.32 \\
\hline & No & 70 & 42.68 \\
\hline & Total & 164 & 100.00 \\
\hline \multirow{3}{*}{ forms of contraception use $(\mathrm{N}=94)$} & Modern methods & 60 & 63.83 \\
\hline & Natural methods & 17 & 18.09 \\
\hline & Traditional methods & 17 & 18.09 \\
\hline & Total & 94 & 100 \\
\hline \multirow{5}{*}{ How long in years } & Less than 1 & 13 & 13.83 \\
\hline & $1-2$ & 23 & 24.47 \\
\hline & $3-5$ & 52 & 55.32 \\
\hline & Above 5 & 6 & 6.38 \\
\hline & Total & 94 & 100 \\
\hline \multirow{4}{*}{ Reasons for using family planning } & Prevent unwanted pregnancy & 50 & 53.19 \\
\hline & Accessible & 22 & 23.40 \\
\hline & Affordable & 12 & 12.77 \\
\hline & Little or no side effects & 10 & 10.64 \\
\hline & Total & 94 & 100 \\
\hline \multirow{6}{*}{ Reasons for not using family planning } & No reason & 10 & 14.29 \\
\hline & Desirous of more children & 14 & 20.00 \\
\hline & Partner/husband's disapproval & 12 & 17.14 \\
\hline & Side effects & 14 & 20 \\
\hline & Against my culture & 8 & 11.43 \\
\hline & Not aware & 12 & 17.14 \\
\hline & Total & 70 & 100 \\
\hline \multirow{2}{*}{ Are you comfortable with the one you are using now } & Yes & 64 & 68.09 \\
\hline & No & 30 & 31.91 \\
\hline & Total & 94 & 100 \\
\hline \multirow[t]{5}{*}{ If no why } & It makes me bleed plenty & 5 & 16.67 \\
\hline & It makes me lose weight & 6 & 20.00 \\
\hline & It makes me put on weight & 7 & 23.33 \\
\hline & Too much vaginal discharge & 8 & 26.67 \\
\hline & I feel nauseated & 4 & 13.33 \\
\hline
\end{tabular}


ISSN (online): 2581-3048

\begin{tabular}{|c|c|c|c|}
\hline & Total & 30 & 100 \\
\hline \multicolumn{2}{|c|}{ Motivating factors } & & \\
\hline \multirow{2}{*}{ Methods available } & Yes & 94 & 100 \\
\hline & No & 0 & 0 \\
\hline \multirow{2}{*}{ All the time would motivate } & Yes & 94 & 100 \\
\hline & No & 0 & 0 \\
\hline \multirow{2}{*}{ Clinic hours convenient? } & Yes & 94 & 100 \\
\hline & No & 0 & 0 \\
\hline \multirow{2}{*}{ Clinic hours convenient } & Yes & 94 & 100 \\
\hline & No & 0 & 0 \\
\hline \multirow{2}{*}{ Free services would motivate you } & Yes & 94 & 100 \\
\hline & No & 0 & 0 \\
\hline \multirow{2}{*}{ Distance near enough would motivate } & Yes & 94 & 100 \\
\hline & No & 0 & 0 \\
\hline \multirow{2}{*}{ Services within reasonable time would motivate } & Yes & 94 & 100 \\
\hline & No & 0 & 0 \\
\hline \multirow{2}{*}{ Friendly protocols/procedures would motivate } & Yes & 94 & 100 \\
\hline & No & 0 & 0 \\
\hline \multirow{2}{*}{ Privacy would motivate } & Yes & 94 & 100 \\
\hline & No & 0 & 0 \\
\hline
\end{tabular}

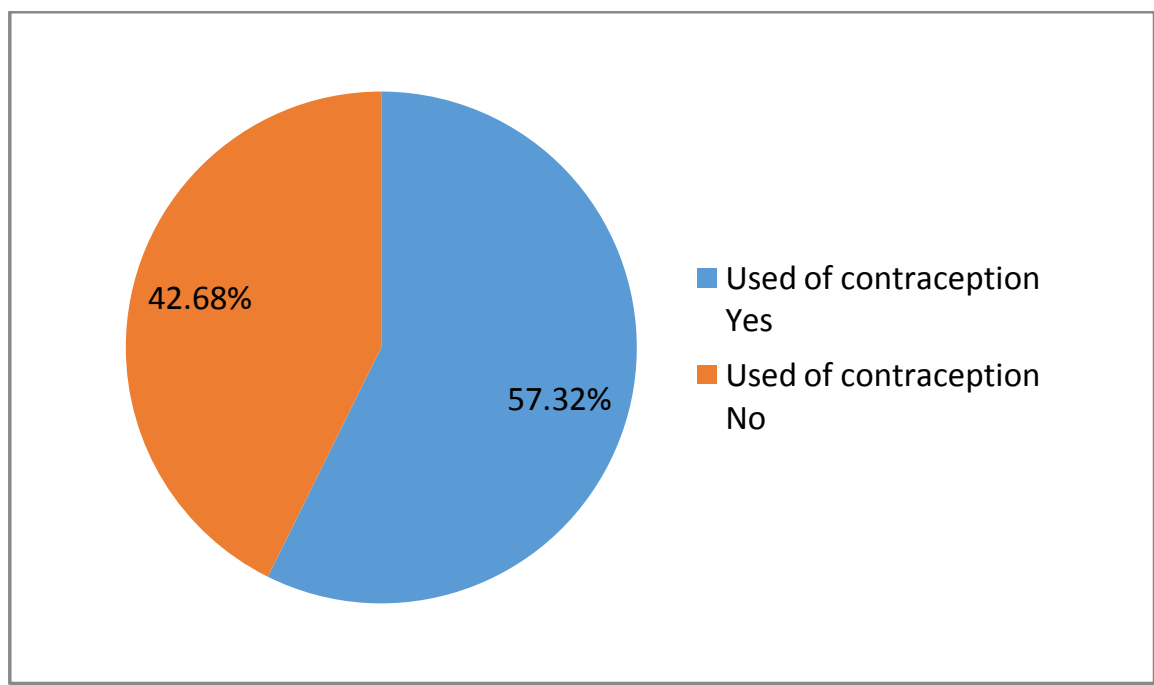

Figure 4: Shows use of contraceptives by respondents

Figure 4 shows that about 94 respondents (57.32\%) said Yes to the use of contraceptives whilst $70(42.68 \%)$ said No to the use of contraceptives.

From table 3 above, Out of 94 respondents that are using contraceptives, 60 respondents $(63.83 \%)$ are using modern methods, $17(18.09 \%)$ each are using natural method and traditional methods respectively. The table also revealed that 13 respondents (13.83\%) have been on family planning contraceptives for less than one year, 23 respondents (24.47\%) for 1-2 years, $52(55.32 \%)$ for $3-5 y e a r s$ and $6(6.38 \%)$ for 5 years and above. 50(53.19\%) of the respondents are using family planning 
ISSN (online): 2581-3048

Volume 5, Issue 6, pp 45-57, June-2021 https://doi.org/10.47001/IRJIET/2021.506010

contraceptives to prevent unwanted pregnancy, 22(23.40\%) said family planning services are accessible to them, 12(12.77\%) said they are affordable while 10(10.64\%) said they experienced no effects with their methods of contraception.

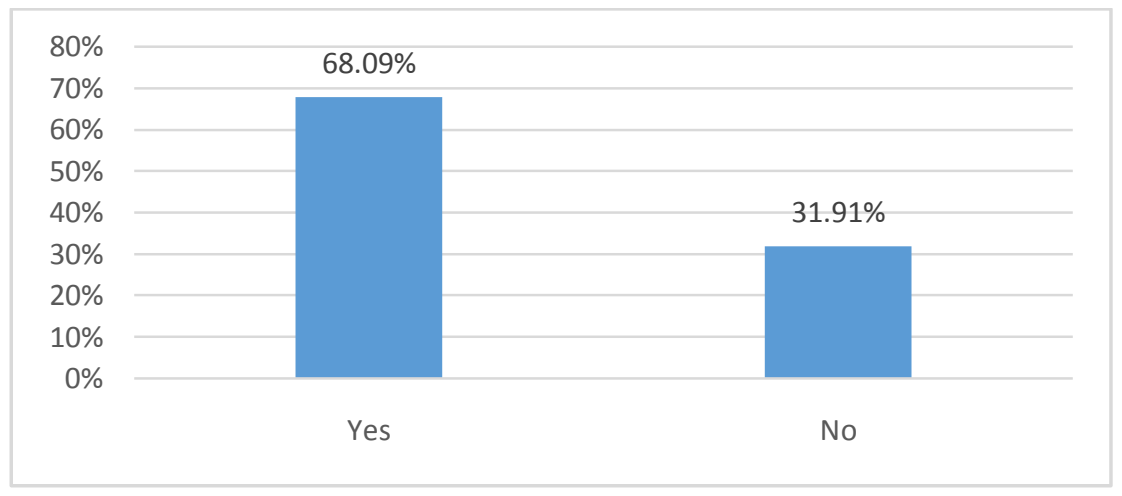

Figure 5: Shows percentages of respondents that are comfortable with the method of contraceptives $(n=94)$

Figure 5 revealed that above more than half of the respondents 64(68.09\%) said they are comfortable with their contraceptive methods they are using while 30(31.91\%) said that they are not comfortable with their methods.

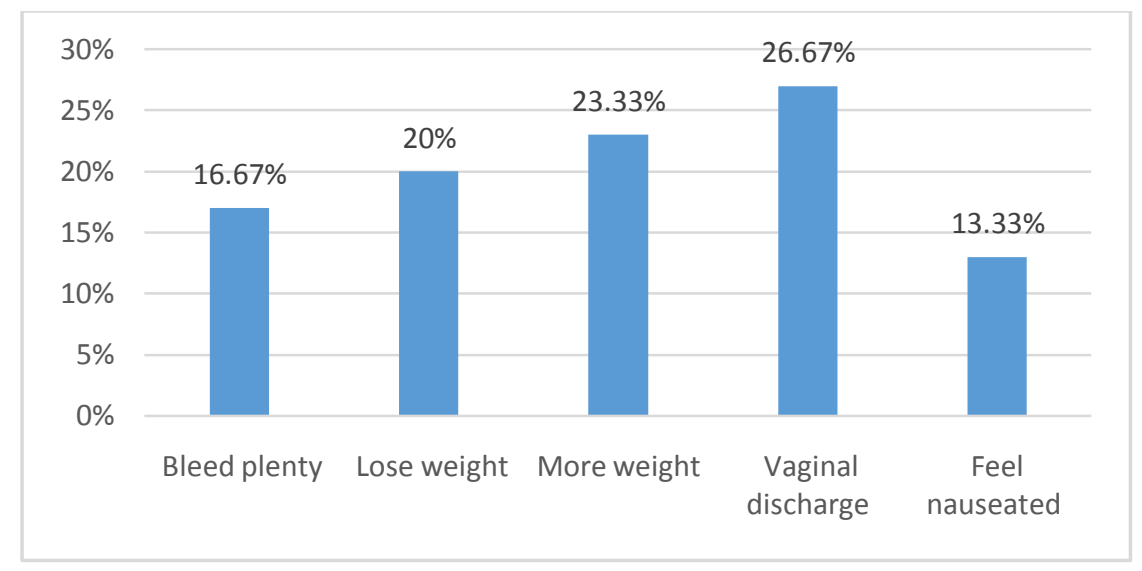

Figure 6: Shows reasons for not using Contraceptives

Figure 6 above, 8 respondents (26.67\%) reported of vaginal discharge due to the contraceptive method they were using, $7(23.33 \%)$ reported weight gain, 6(20\%) weight loss while 5(16.67\%) reported of bleeding and 4(13.33\%) reported feeling nauseated with their method.

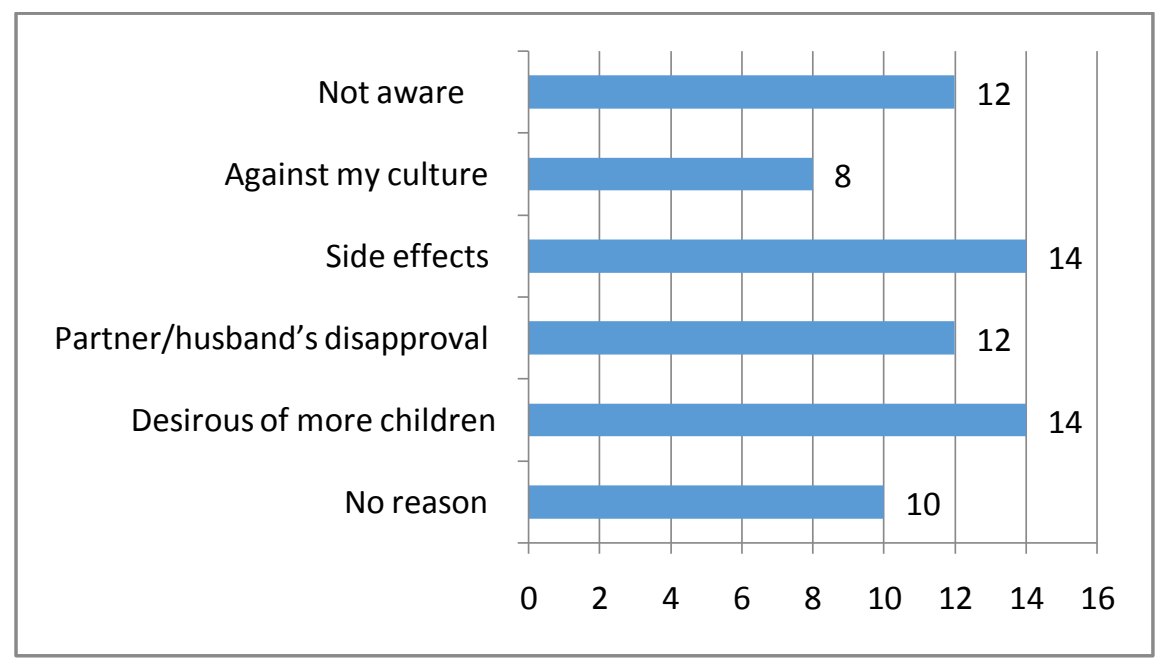

Figure 7: Shows Reasons for not using family planning Contraceptives $(\mathbf{N}=\mathbf{7 0})$ 
ISSN (online): 2581-3048

Volume 5, Issue 6, pp 45-57, June-2021 https://doi.org/10.47001/IRJIET/2021.506010

From figure 7 Out of 70 respondents 14(20\%) each recorded for desirous more children in using contraceptives and having side effect in the use of contraceptive respectively. 12(17.14\%) of the respondents said the reason for not using contraceptives was as a result of partner/husband's disapproval whilst $8(11.43 \%)$ respondents said using contraceptives is against their culture and $12(17.14 \%)$ are not aware.

\subsubsection{Section D: Availability of contraceptive $(N=94)$}

Table 4: Availability of contraceptive

\begin{tabular}{|c|c|c|c|}
\hline \multirow{2}{*}{$\begin{array}{l}\text { Do you get family planning commodities } \\
\text { easily }\end{array}$} & Yes & 54 & 57.4 \\
\hline & No & 40 & 42.6 \\
\hline & Total & 94 & 100 \\
\hline \multirow[t]{4}{*}{ If no, why } & Don't know where to get them & 8 & 20 \\
\hline & They are expensive & 6 & 15 \\
\hline & $\begin{array}{l}\text { The health workers are not } \\
\text { accommodating }\end{array}$ & 10 & 25 \\
\hline & Clinic hours are not convenient & 16 & 40 \\
\hline & Total & 40 & 100 \\
\hline \multirow[t]{5}{*}{ How to improve the availability } & Health education (to improve utilization) & 15 & 37.5 \\
\hline & Improved supply/access & 10 & 25 \\
\hline & Government should reduce price & 6 & 15 \\
\hline & Other specify & 9 & 22.5 \\
\hline & Total & 40 & 100 \\
\hline
\end{tabular}

From table 4 above, out of the 94 respondents that have the availability of contraceptives use, more than half of the respondents amounting to $54(57.4 \%$ ) said that it was easy to get family planning contraceptives methods while 40 respondents $(42.6 \%)$ said it was not easy to get family planning commodities. See figure below;

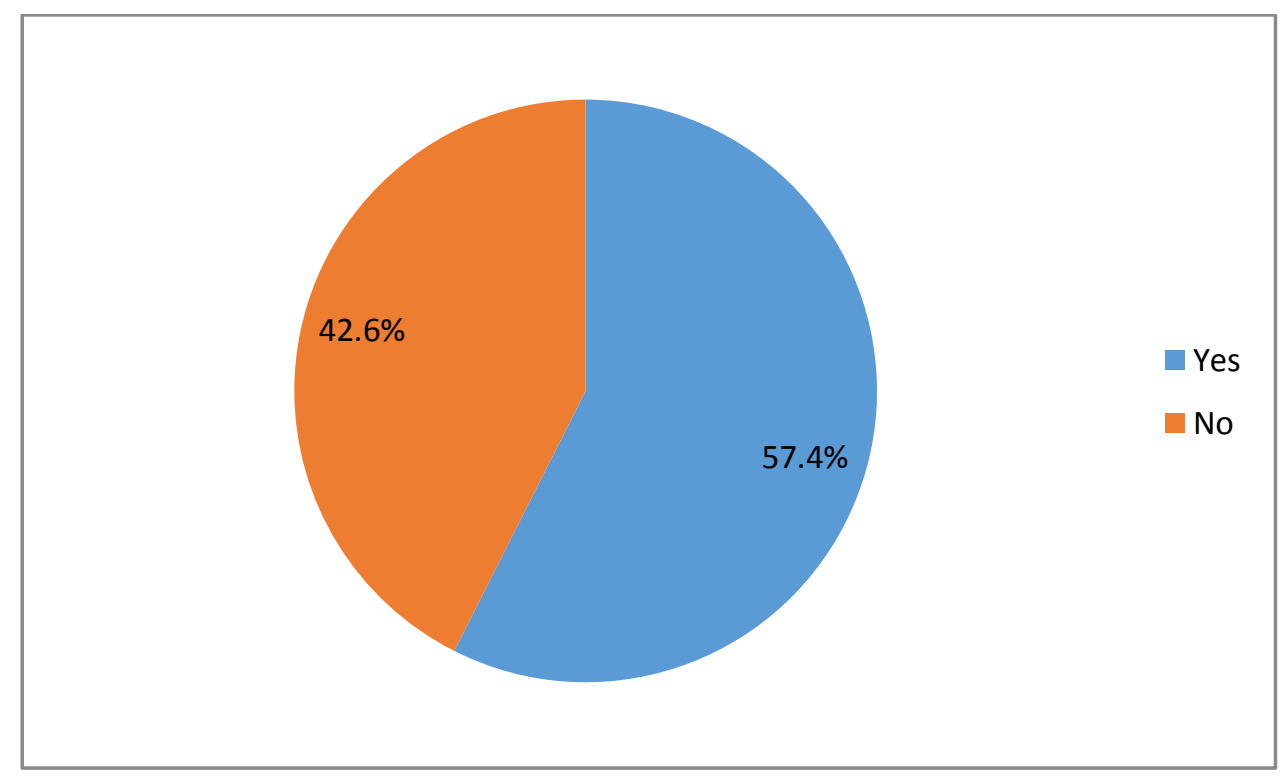

Figure 8: Shows if the respondents get family planning contraceptives easily

From figure 8 above, 54 respondents (57.4\%) said Yes to get family planning commodities easily whilst 40(42.6\%) said No. 


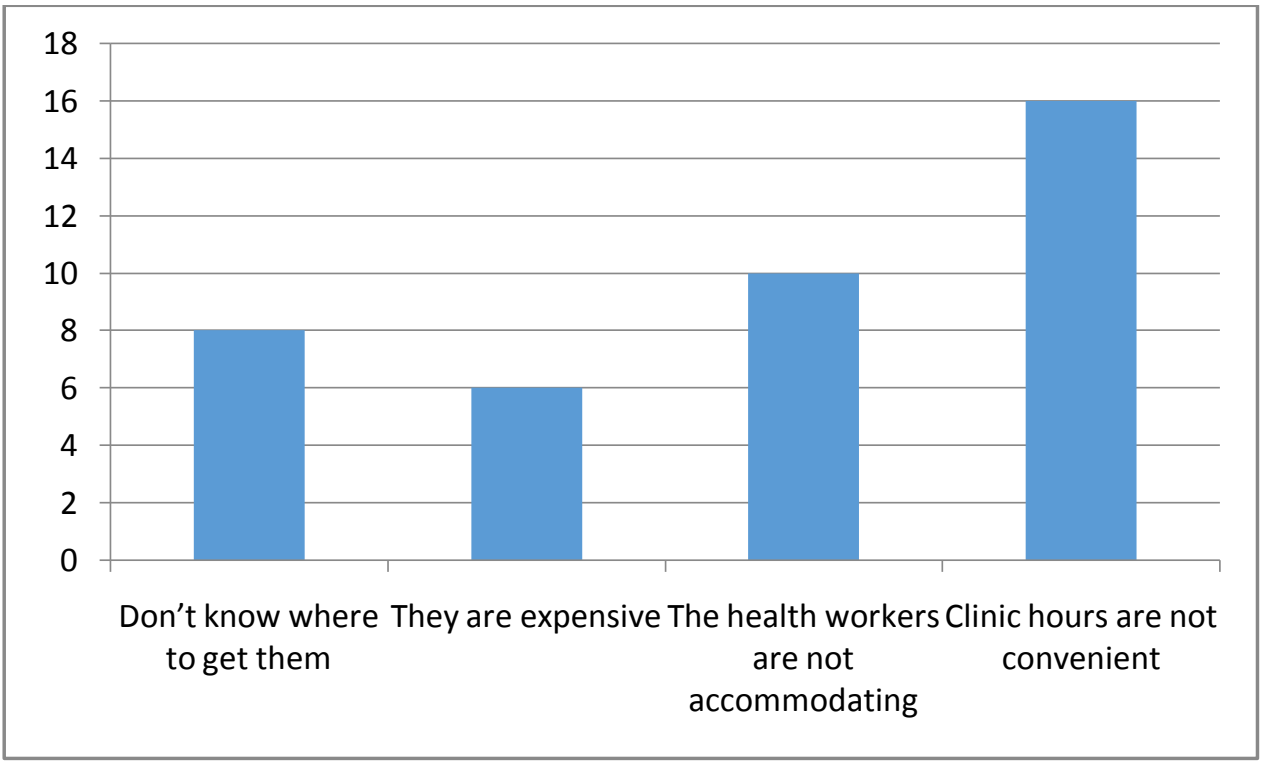

Figure 9: Shows reasons for not using contraceptives by respondents

From figure 9, 8 respondents (20\%) don't know where to get the contraceptives whilst 6(15\%) said the contraceptives were expensive. About 40 respondents that recorded $37.5 \%$ said the clinic hours are not convenient whilst $10(25 \%)$ said the health workers are not accommodating.

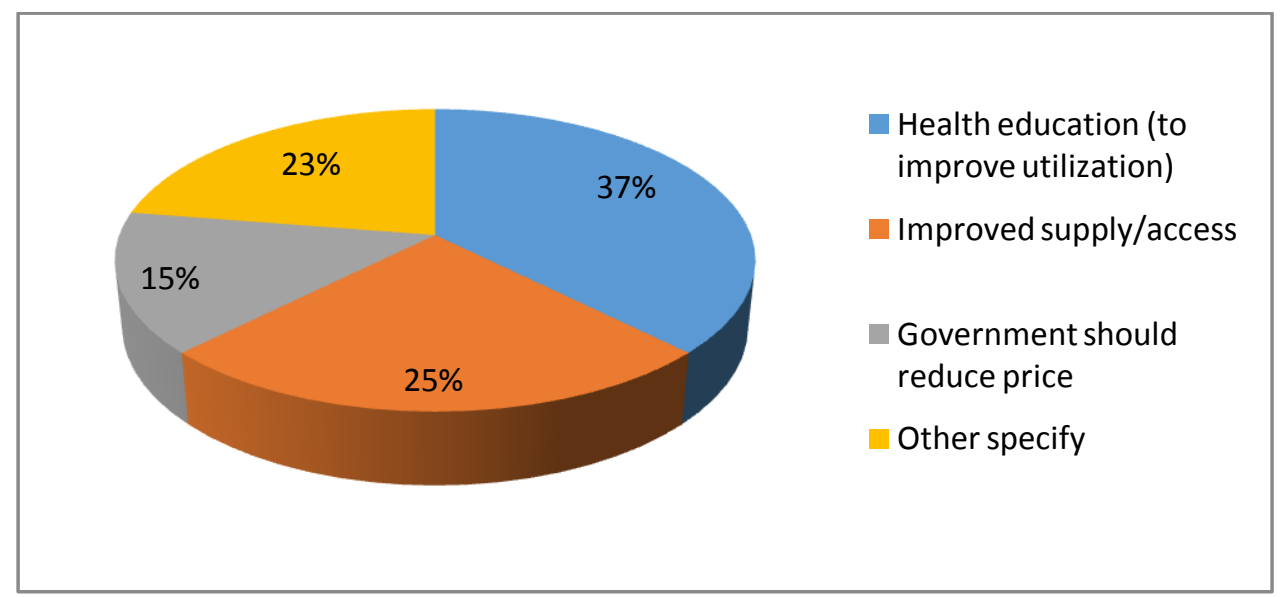

Figure 10: Shows on how to improve the availability of the use of contraceptives by respondents

Figure 10 shows that about 15 of the respondents (37.5\%) indicated one way to improve the availability of contraceptives use among adolescence is by health education followed by 10 respondents(25\%) that said by improved supply/access whilst $6(15 \%)$ said that Government should reduce the price of contraceptives to attract its demand.

\section{DISCUSSION OF FINDINGS}

This study shows that all the participants were willing to take part in the study and majority was between the ages 15 19 years. It also revealed that majority of them were single and only quite few of them were non-school going girls. This study is similar to that done in Nigeria were almost $95 \%$ of them were school going children.

The findings from this study show that utilization of contraceptives was higher among Christians than those practicing Islam. This shows religion has an effect on contraceptive use. This has been found in similar studies Southern Sudan were majority of the participant that were practicing Islam did not used any family planning method.

Utilization was also found to be higher among those with formal education than those without any formal education. It is higher among those with primary and secondary level of education with financial support from parents. Therefore social class and education were found to correlate positively with contraceptive uptake when compared with a similar study done South Africa in 2007. 
1. Our findings show that a lot of adolescents get information about contraception from health workers. However, about half of these adolescents equally obtain the information from friends, relations and mass media. These sources of information may involve dissemination of a lot of misconceptions, which will not guide appropriate decisionmaking regarding family planning. The implication of the findings is that much advocacy on use of modern methods of family planning needs to be done. Family planning serves as a way of improving the socio-economic well-being of any society and is also pivotal in reducing the incidence of abortions and its complications.

The study also shows that majority of the adolescents had awareness of family planning and contraception. However, quite a large number (43\%) do not used family planning methods. The majority of the participants know at least one form of contraceptive method. This is similar to findings in other studies carried out within and outside of the country (WHO 2008). The knowledge of various modern methods was very high except for the female condom which was low.

Our findings also revealed that majority of the adolescent girls were using Family planning methods to prevent unwanted pregnancy.

Findings of the study confirmed few barriers identified in previous studies. Nevertheless, findings provided some new insight into the perception that impedes the use of family planning by girls.

2. In a study finding in Pakistan DHS 2012-13 condoms were the most commonly used, this is in contrast to the findings of this study where the pill is the most commonly used contraceptive followed by the injectable, natural and Intrauterine Contraceptive Device (IUCD) methods.

3. There were persistent problems of accessibility, affordability, and attitude of family planning service providers in the rural areas of Sierra Leone. One participant said "we want to practice family planning but it is not within our reach; it is hard for us to reach family planning services in health centers because they are far away from our residence." The clinic hours also need to be modified and made adolescent friendly.

Overall, the findings suggest that improved family planning messaging, broader availability of contraceptive methods, expanded and reliable operating hours, consistent supplies, and more counseling would improve contraceptive use and continuation by adolescent girls in Safroko Limba Chiefdom.
There is need for renewed commitment to social programmes to address the socio-economic status of women in the country particularly women in advanced reproductive age groups. As found in the study and consistent with finding in a recent study [WHO 2009], women with lower socio-economic characteristics such as uneducated women, unemployed women and women in poorest household had higher likelihood of not using contraceptive in spite of their advanced age. This not only increases the risk of unintended pregnancies among them but also increases lifetime risk of maternal deaths or disabilities among them. Existing policy initiatives have stressed expanding contraceptive distribution and logistics; it is however doubtful that contraceptive prevalence will improve in the country without corresponding improvement in the socio-economic status of women. Large numbers of women still do not have access to basic education, unemployment is more widespread among women, and several socio-cultural practices such as property inheritance, child marriages, land tenure system and gender-based violence still adversely affect economic productivity of women in the country [33]. Such social condition does not encourage contraceptive use irrespective of age. It is therefore important for government in the country to give more recognition to the fact that social condition of women in the country may hinder the attainment of the contraceptive target of increasing modern contraceptive prevalence by $2 \%$ yearly. An avenue for demonstrating such recognition is to ensure that women concerns are integrated into all social and economic development planning programmes at all levels of governance in the country.

\subsection{Summary}

Low use of contraceptives continues to be a significant public health problem throughout the low income countries, particularly in Sub-Saharan Africa and South Asia.

It is for this reason that this study sought to assessing barriers to contraceptive use amongst adolescents in the Safroko Chiefdom, Bombali District, North East of Sierra Leone. The purpose of this study was to assess knowledge of contraceptives and barriers to contraceptive use amongst adolescents in the Safroko Chiefdom, Bombali District, North East of Sierra Leone.

The relevant factors significantly influenced the Low use of contraceptives were ignorance, religion, illiteracy, cultural believes, accessibility, affordability, social status, and attitude of health staff.

\subsection{Conclusion}

Prevalence of contraceptive low use among adolescents the study area is high and majority was from Muslims. 
The relevant factors significantly influenced the Low use of family planning services were religion, illiteracy, accessibility, availability, affordability, employment status, and attitude of health staff.

\subsection{Recommendations}

1. The Sierra Leone Government should ensure continuous provision of Family planning commodities, as decided by the Focus Group.

2. Health education should be reinforced at health facilities, religious houses and at community level to improve adolescents' knowledge on the benefits of Family planning.

3. A large multicenter study should be undertaken to determine the burden of low use of family planning services in the study area.

4. Further research should be undertaken on a much large scale to cover the entire nation.

\section{REFERENCES}

[1] United Nations DoEaSA, Population Division: World Contraceptive Use 2012, POP/DB/CP/Rev2012. In.; 2012.

[2] Guttmacher Institute: ADDING IT UP: Investing in Contraception and Maternal and Newborn Health, 2017. In.: Guttmacher Institute; 2017.

[3] Say Lale, Chou Doris, Gemmill Alison, Tunçalp Özge, Moller Ann-Beth, Daniels Jane, Gülmezoglu A. Metin, Temmerman Marleen, Alkema Leontine: Global causes of maternal death: a WHO systematic analysis. The Lancet Global Health 2014, 2:e323333.

[4] Ashford Lori: UNMET NEED FOR FAMILY PLANNING: Recent Trends and Their Implications for Programs. In. Washington, DC: Population Reference Bureau; 2003.

[5] Center for Reproductive Rights (the Center), United Nations Population Fund (UNFPA): THE RIGHT TO CONTRACEPTIVE INFORMATION AND

\author{
ISSN (online): 2581-3048 \\ Volume 5, Issue 6, pp 45-57, June-2021 \\ https://doi.org/10.47001/IRJIET/2021.506010
}

SERVICES FOR WOMEN AND ADOLESCENTS. In. United States: Center for Reproductive Rights; 2010.

[6] WHO: Family planning/Contraception: Fact sheet N³51. In. Geneva, Switzerland: WHO; 2015.

[7] Ochako Rhoune, Mbondo Mwende, Aloo Stephen, Kaimenyi Susan, Thompson Rachel, Temmerman Marleen, Kays Megan: Barriers to modern contraceptive methods uptake among young women in Kenya: a qualitative study. BMC Public Health 2015, 15(118).

[8] Bryce, J, Victora, C, Berman, P. Fulfilling the health agenda for women and children: the 2014report ,2014.

[9] Leone,S. The status of women and children in Sierra Leone,

https://books.google.co.in/books/about/The_status_of _women_and_children_in_Sier.html?id=cLa3AAAA IAAJ\&redir_esc $=y$

[10] Leone,S. Healthsurvey, 2008, http://www.mamaye.org.sl/sites/default/files/evidenc e/SL $\% 2$

[11] Fertility and F/P https://www.ncbi.nlm.nih.gov > pmc > articles > PMC5907724

[12] Scaling up F/P in SL https://journals.sagepub.com > doi > full

[13] F/P key to development https://awoko.org , 2018/06/29 > sierra-leone-news-family-planning-keyt...

[14] Opposition to contraception https:/www.nytimes.com > 2006/05/07 > magazine > 07contraception

[15] Unmet need of contraception https://www.guttmacher.org > report > unmet-needfor-contraception-in-de...

[16] Barriers DOI: https://doi.org/10.1016/j.contraception.2014.12.003

[17] Prevention of teen age preg https://www.afro.who.int > sites > default > files > Sierra Leone National Re...

[18] UNFPA report https://www.unfpa.org > sites > default > files > pub-pdf > UNFPA_Supplie...

\section{Citation of this Article:}

Evelyn Abie Bangura, Allieu Badara Kabia, Mohamed Gbeshay Sheku, Fawulay Yibba Marah, Magenda Kamara, Issa Bangura, Morlai Francis Kargbo, "Assessing Barriers to Contraceptive Use amongst Adolescents in the Safroko Chiefdom, Bombali District, North East of Sierra Leone" Published in International Research Journal of Innovations in Engineering and Technology - IRJIET, Volume 5, Issue 6, pp 45-57, June 2021. Article DOI https://doi.org/10.47001/IRJIET/2021.506010 